\title{
El acto cooperativo. Fallo anotado
}

\author{
Cesar Juan Ariel Omarini
}

Juzg. Civ. y Com. Diamante, E.R. -15/5/97-; Cámara de Apelaciones Civ. y Com. Paraná, Sala I-17-7-98-, Sala Civ. y Com. Superior Tribunal de Justicia (E.R) 18/12/98; Causa «W. A c/ Coop. Agricola Unión Reg. Ltda.—Sumario» Expte. N* 471/95.

A.W. asociado de la Cooperativa Agrícola Unión Regional Ltda. de la ciudad Ramirez, Dto. Isletas, Dpto. Diamante, interpone ante

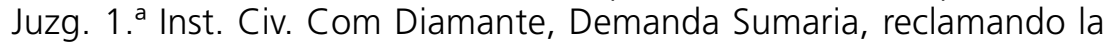
restitución de su aporte de capital activo, que el citado tenía ingresado en la Cooperativa, y por cuyo uso esta le abona intereses. Fundamenta su acción en ser asociado de esta, y se sustenta en su derecho de propiedad del dinero aportado. Y agrega Estatutos y documental que acredita su aporte de capital. Ofrece Pruebas y acredita gestión extrajudicial previa. Notificada Demanda la Cooperativa compulsada, contesta demanda sosteniendo que la acción es improcedente, pues el depósito voluntario de A.W, un asociado de la Cooperativa Demandada y por tanto sometido al encuadre legal de la Ley 20.337, y Estatutos de la entidad que el Propio actor agrega al demandar. Sometida la relación a la regulación legal de normas del Derecho Cooperativo, y a su vez invocando la Cooperativa ahora demandada que entre las partes litigantes existe un acto Cooperativo, regulado por las normas antes citadas. Y específicamente, señala la accionada, que no le asiste a A.W. derecho a reclamar su aporte de capital activo que ingresa voluntariamente, y por el cual percibe interés, por ser aplicable el art. 23 de los Estatutos que claramente determina, «que en épocas desfavorables situación económica, y hasta tanto no se 
haya superado la misma, no se devolverá dicho aporte Capital. Y el Estatuto -invoca la demandada- que el propio actor agrega en prueba de su demanda, le obliga por haberlo aceptado al asociarse, como conjunto de normas que establecen derechos y obligaciones de la Cooperativa y asociado.-Agrega la accionada Balance de la Cooperativa que acredita su déficit financiero, que la actora consiente. En primera instancia el Dr. José María Vergara, sentencia rechazando la Demanda exponiendo» que no le asiste razón al actor para pedir el reintegro de los fondos que dice tiene depositados en una cuenta especial de la demanda. No es punto controvertido que el accionante es socio de la Cooperativa demandada y, como tal acepta las disposiciones estatutarias y reglamentos de la entidad (Cfr. art. 9 Cap. III del Estatuto de la Cooperativa Agrícola Unión Regional Ltda. Fs. 50) obligándose a cumplir los mismos (Cfr. art. 10 Cap. III del referido Estatuto obrantes hojas citadas). Consecuentemente el actor acepta que lo integrado por capitalización de cuotas sociales, podrá ser retirado por el socio cuando las circunstancias económicas financieras de la Cooperativa lo permita (CFR art. 23 Cap. IV del Estatuto social). La Cooperativa demandada que en caso de autos se ha dado el presupuesto del art. 23 que obsta el reintegro de depósito, situación económica negativa que ilustra la pericial contable de fs 100/112 que no ha merecido ni observación ni reproche de las partes...»-Con tales argumentos entre otros- el Juez de la Instancia Rechaza la demanda. Con costas.

Se alza A.W., por sus mandatarios, apelando la sentencia, y consecuencia de la misma la causa ingresa a la Cámara de Apelaciones Civ. Com Paraná — Sala I-, donde se valora lo actuado y las sendas expresiones de agravios de ambas partes. Corresponde - previo sorteo ritual-que consienten litigantes; al Dr. Luis María Ortiz Mallo, primer voto, quien expone que el "A-Quo» ha partido de una premisa correcta, que no es otra que el actor es asociado de la Cooperativa, y como tal acepta las disposiciones estatutarias y reglamentos de la entidad, obligándose a cumplir los mismos, por lo cual acepta que lo integrado por capitalización de cuotas sociales podrá ser retirado por el socio cuando las circunstancias económicas financieras de la cooperativa lo permiten. En base a ello agrega el camarista mencionado, y teniendo en cuenta lo dispuesta en el art. 4 de la Ley 20.337, que considera que son actos cooperativos los realizados entre la cooperativa y el asociado o por aquellas entre sí en cumplimiento del objeto social. Y la relación entre actor y demandada reviste tal naturaleza, sometida 
por consiguiente a los Estatutos sociales. Resalta prueba testimonial del Cdor. Paulina —Auditor Externo de la Cooperativa-, y la evidente demostración del déficit económico financiero de la demandada, con la prueba documental representada por el ejercicio económico N.$^{\circ} 63$, que consienten ambas partes, y en definitiva se expide que la demanda ha sido correctamente rechazada. Los Dres. Cabrera y Blanc se adhieren por iguales consideraciones, por lo que en definitiva se resuelve Confirmar la Sentencia. Notificada la actora esta se alza en Casación, y concedido el extraordinario, la causa arriba a la Sala Civ. y Com. del Superior Tribunal de Justicia AQUÍ la Sala de mención, expresa que «se ha configurado un aporte voluntario susceptible de ser restituido cuando las condiciones económicas financieras lo permitan de acuerdo al art. 23 de los estatutos a partir de la calificación de la relación que vincula a las partes como un acto cooperativo en los términos del art. 4 de la Ley 20.337». Y concluye que la actora no refuta no haber probado lo contrario, considerando que su encuadre legal no logra conmover el fallo impugnado, y destaca la insuficiencia de la fundamentación del quejoso, por lo que RECHAZA LA INAPLICABILIDAD DE LA LEY.

Asistimos, sin duda, a un expreso reconocimiento del acto Cooperativo, de propia naturaleza jurídica, sometida expresamente a la regulación legal de la Ley 20.337, Estatutos Sociales y reglamentos internos de las secciones de la cooperativa, o sea definitivamente a las normas del derecho Cooperativo (Cfr. Memorial Cooperativo Dr. Cesar Omarini, J. E. Rios, T 74 Pag. 853). Pues la Cooperativa es una asociación autónoma de personas que se han unido voluntariamente, bajo el amparo legal de los Estatutos, que ellos mismos elaboran y aprueban o que aceptan al ingresar, y para satisfacer necesidades comunes, por medio de una empresa de propiedad conjunta y democráticamente controlada; Siendo principios que sustentan esta empresa aprobados en Congreso de la ACl - Manchester setiembre de 1996: Adhesión abierta y voluntaria; control democrático de los socios; participación económica de los asociados; Autonomía e Independencia; Educación e Información del Asociado; Cooperación entre Cooperativas, y compromiso con la comunidad.

El fallo de mención convalida la vigencia de la empresa cooperativa, y sustancialmente la existencia jurídica del Acto Cooperativo, con la convicción que el mismo es figura elemental de una Cooperativa, y quien no lo practica no es tal. Todas argumentaciones precedentes y 
expuestas en las tres instancias Judiciales no solo dá vigencia del acto cooperativo, sino igualmente a las normas del Derecho Cooperativo, al someter la relación de AW y Caur a sus estatutos, y reglamentaciones internas, soslayando con acierto la normativa del derecho civil y comercial, que debe operar en subsidio.

Asistimos a un nuevo y preciso reconocimiento del acto cooperativo, y de la normativa que debe regular su funcionamiento dentro del ámbito jurídico, que nuestros tribunales, ya dieran vigencia en ocasión de otra causa que tuvimos que abordar - (Cámara de Apelaciones, Sala II fallo del 20/2/90, Casación convalidante por Sala Civ. y Com. causa «COOP. AGRICOLA UNION REGIONAL»C/ M. B. D.- Ordinario).-

Este nuevo logro nos vitaliza, y nos motiva a continuar litigando y perseverando por el afianzamiento del acto cooperativo, pero indudablemente el mismo será un tema abierto a nuevos y profundos desarrollos.

Y el caso citado que nos tocó «afrontar» en el ámbito de nuestros tribunales, nos vitaliza, no solo por ser una reiteración del ya obtenido y citado supra, sino haberse expresado con evidencia irrefutable el acto cooperativo, y normativa del derecho cooperativo como sustancial fundamento de tres sentencias judiciales.

Y en estricta relación con el tema que abordamos, consideramos procedente resaltar, que las obligaciones, nacen de dos fuentes fundamentales: la ley y la voluntad, sin embargo cuando los autores aluden a la voluntad generalmente insisten en el contrato como fuente generadora de obligaciones, olvidándose que en la sociedad moderna, de masas, se desarrolla con gran fuerza el llamado acto colectivo, como es el caso de las cooperativas donde en gran medida las obligaciones provienen de la voluntad de la mayoría de votos a diferencia del contrato, que incluso obliga a la minoría que se opusieron.

Y en el fallo que anotamos A.W., actor está obligado e impedido a obtener el reintegro de su aporte de su capital activo, por voluntad de la mayoría expuesta en una Asamblea donde se aprobó el Estatuto.

Y esencialmente la Cooperativa es una institución intermedia entre el individuo generador de obligaciones a partir del contrato, y el estado a partir de la Ley. 
Definitivamente, mediante esta publicación, expongo y manifiesto mi indeclinable decisión de mantenerme activamente vinculado a reflexiones sobre temas jurídicos que atañen al sector cooperativo, expresando mi agradecimiento a la Coop. Agrícola Unión Regional y al Dr. Ricardo Miguel Angel KLUG, con quien he participado y compartido Jornadas y Congresos Nacionales e Internacionales del Derecho Cooperativo.

Gral. Ramírez, Marzo 07 de 1999.

\section{Dr. César Juan Ariel Omarini}

Asesor Legal Coop. Agric. Unión Reg.

Miembro Fundador Sección Argentina Asociación Internacional Derecho Cooperativo.

Participante Pleno, IV Congreso Continental De Derecho Cooperativo Brasilia Agosto 1992.

Observador II Cumbre Continental Dirigentes Cooperativos - Montevideo Marzo 1993.

Fundador e integrante Junta Letrados Cooperativos y Promotor Instituto Derecho Cooperativo

Coleg. Abogados de Entre Rios. 